\title{
The investigation of expanded polystyrene creep behaviour
}

\author{
Aleksey Zhukov ${ }^{1}$, Vyacheslav Semenov ${ }^{1}{ }^{*}$, Ivan Gnip $^{2}$, and Saulus Vaitkus ${ }^{2}$ \\ ${ }^{1}$ Moscow state university of civil engineering, Yaroslavskoye shosse, 26, Moscow, Russia, 129337 \\ ${ }^{2}$ Scientific Institute of Thermal Insulation Vilnius Gediminas Technical University (VGTU), 10223 \\ Sauletekio al. 11, Vilnius, Lithuania
}

\begin{abstract}
The results obtained in long-term testing under constant compressive stress of the cut from the Slabs EPS 50/100 and EPS 150 with the density ranging from 15 to $24 \mathrm{~kg} / \mathrm{m}^{3}$, which were manufactured by the same manufacturer by foaming EPS solid granules (beads) in closed volume. The creep strain of the above described specimens was used as a criterion for estimating the deformability of the EPS slabs under long-term compressive stress. It was measured using special stands EN 1606, maintaining constant stress during the fixed time interval $t_{n}=122$ days. Creep strains were determined by the methods described in EN 1606 for constant stress $\sigma_{\mathrm{c}}=0.35 \sigma_{10 \%}$ (compressive stress $\sigma_{10 \%}$ was determined in accordance with EN 826:2013. The long-term compressive stress measurement error did not exceed $1 \%$, while the creep strain measurement error was not larger than $0,005 \mathrm{~mm}$. The tests were conducted at the ambient temperature of $(23 \pm 2)^{\circ} \mathrm{C}$ and relative humidity of $(50 \pm 5) \%$. The long-term constant compressive load $\sigma_{\mathrm{c}}=0.35 \sigma_{10 \%}$. The method of mathematical and statistical experimental design optimization models taking into account the thickness of specimens is proposed to determine the creep compliance $I_{c}\left(t_{n}\right)$ the creep strain $\varepsilon_{c}\left(t_{n}\right)$ and predictive point estimate of creep strain $\varepsilon_{c}(T)$. Graphical interpretation of the abstained models is also presented. It should be noted that the abstained equations may be used in practice for estimating the creep strains at time $t_{n}=122$ days and predictive estimates of $\varepsilon_{c}(T)$ for the load time of 10 years.
\end{abstract}

\section{Introduction}

The criterion for the effectiveness of any insulation, in addition, the thermal characteristics of the material are its resistance operational and manufacturing costs. Foamed plastics are used in transport systems as an insulating bases pavement $[1,2]$. Therefore, it is important to assess their strength properties and creep. Foamed plastics are used in transport systems as an insulating bases pavement. Therefore, it is important to assess their strength properties and creep [3, 4].

According to EN 1606:1996/A1:2006 (GOST EN 1606-2011), EPS creep behaviour should be studied by considering square specimens cut from EPS slabs with the side of 50,

* Corresponding author: science-isa@yandex.ru 
$100,150,200,300 \mathrm{~mm}$ and thickness equal to slab thickness. The creep level of expanded polystyrene is declared now based on the investigation of the specimens $(50 \times 50 \times 50) \mathrm{mm}$ (EN 13163:2013. (GOST R 56148-2014)).

The results obtained in standard tests often do not correlate with building material behaviour in real conditions. The investigations described in the paper presents were aimed at optimizing the thickness of EPS specimens of various densities for determining their creep strains under constant compressive stress $[5,6]$.

In this paper presents, the results obtained in long-term testing under constant compressive stress of the specimens cut from the slabs EPS 80, EPS 100 and EPS 150 with the density ranging from 15 to $24 \mathrm{~kg} / \mathrm{m}^{3}$, which were manufactured by the same manufacturer by foaming EPS solid granules (beads) in a closed volume. Thus, the slabs EPS 150 were made of the raw material (EPS granules) F 295 available from BASF (Ø 1,0$2,3 \mathrm{~mm}$ ), the slabs EPS 100 were made of the granules F $215 \mathrm{~N}$ available from BASF ( $\varnothing$ $1,0-2,0 \mathrm{~mm}$ ) and the slabs EPS 80 were made of the granules NF-514 available from STYROCHEM (Ø 1,4-2,5 mm).

\section{Experimental}

The research methods and statistical design of experiments. Square specimens with the side of $b=100 \mathrm{~mm}$ and thickness $d$, equal to the thickness of the tested EPS slabs (50,75 and $100 \mathrm{~mm}$ ) (accepted in accordance with EN 1606), have been tested [7, 8].

The creep strain of the above described specimens was used as a criterion for estimating the deformability of the EPS slabs under long-term compressive stress. It was measured using special stands EN 1606, maintaining constant stress during the fixed time interval $t_{n}=122$ days. Creep strains were determined by the methods described in EN 1606 for constant stress $\sigma_{\mathrm{c}}{ }^{1}=0.35 \sigma_{10 \%}$ (compressive stress $\sigma_{10 \%}$ was determined in accordance with EN 826:2013 (GOST EN 826-2011)). The long-term compressive stress measurement error did not exceed $1 \%$, while the creep strain measurement error was not larger than $0,005 \mathrm{~mm}$. The tests were conducted at the ambient temperature of $(23 \pm 2)^{\circ} \mathrm{C}$ and relative humidity of $(50 \pm 5) \%$.

Based on the data obtained in testing EPS specimens under short-term compression, the regression line for compressive stress $\bar{\sigma}_{10 \%}$ is given (Fig. 1), depending on the results obtained in determining their density EN 13163.

Statistical processing of the experimental data for specimens under long-term compressive stress was made for the experiment of $t_{n}=122$ days. Relative creep strains $\varepsilon_{c}(t)$, $\%$, were determined by the formulas given in EN 1606 and approximated by the Findley equation $[9,10]$ :

$$
\bar{\varepsilon}_{c}(t)=b_{0} t^{b_{1}}
$$

where $\bar{\varepsilon}_{c}(t)$ is the mean creep strain value at time $t, \% ; b_{0}, b_{1}$ are the constants, depending on the material properties; $t$ is time, $h$.

Creep strains may be quantitatively measured by creep compliance, which is only the time function:

$$
I_{c}(t)=\frac{\varepsilon_{c}(t)}{\sigma_{c}},
$$

where $I_{c}(t)$ is a relative unit creep strain at the fixed time $t$, caused by unit stress applied at time $t \leq 15 \mathrm{~s} ; \sigma_{c}$ is constant compressive stress at time $\mathrm{t}$; $\mathrm{t}$ is readout time.

\footnotetext{
${ }^{1}$ According to EN 1606, the levels of $\sigma_{10 \%}$ corresponding to $0.15 ; 0.20 ; 0.25 ; 0.30$ and 0.35 are recommended for stress $\sigma_{\mathrm{c}}$.
} 
Thus, creep strains may be obtained by multiplying the creep compliance caused by the unit stress by a certain stress $\sigma_{c}$ :

$$
\varepsilon_{c}(t)=\sigma_{c} \cdot F\left[I_{c}(t)\right],
$$

where $F\left[I_{c}(t)\right]$ represents some time function, expressing the increase in the creep strain caused by the application of unit stress equal, for example, to $1 \mathrm{MPa}$.

Then,

$$
I_{c}(t)=\frac{\varepsilon_{c}(t)}{\sigma_{c}}=F\left[I_{c}(t)\right]
$$

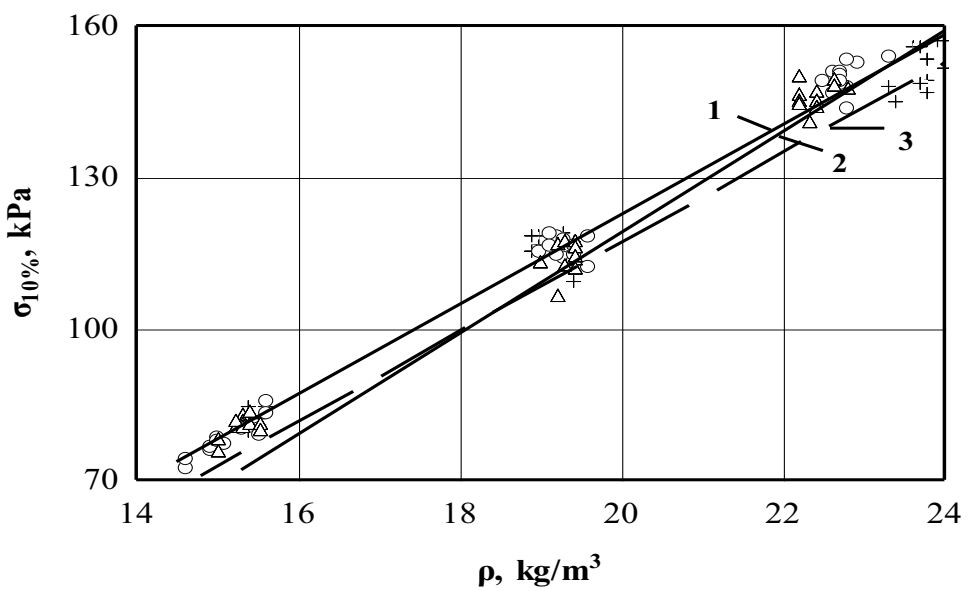

Fig. 1. The empirical regression lines for EPS specimens under short-term compressive stress $\bar{\sigma}_{10 \%}$ based on the results obtained in determining their density, $\rho ; 1,2$ are the regression lines for the mean $\left(\sigma_{10 \%}\right)$ value plotted in accordance with EN 13163, respectively; 3 same for the lower (minimum) bound of stresses $\sigma_{10 \%}$, according to the experimental data. Points are the experimental data for slab specimens of the thickness, mm: + means $50 ; \circ$ means $75 ; \Delta$ means 100.

In processing the experimental data, three output parameters $\left(I_{c}\left(t_{n}\right), \varepsilon_{c}\left(t_{n}\right), \varepsilon_{c}(T)\right)$ and two controlled factors (expanded polystyrene density $\rho$, and the specimen thickness $d$ ) were used. The slabs with the density ranging from 15 to $24 \mathrm{~kg} / \mathrm{m}^{3}$ were tested according to a full factorial experiment of the type $N=n^{k}$ (where $n$ is the number of levels and $k$ is the number of factors). The number of tests was $N=3^{2}=9$ (there were three specimens of the same density in a set to ensure the reliable results under compressive stress) were tested $[11,12]$.

In testing, the values of the factors were maintained at the fixed level according to the experiment design. For simplifying the record of the experimental conditions and experimental data processing, the factors were encoded by the formula:

$$
x_{j}=\frac{\bar{x}_{j}-\bar{x}_{j(i)}}{I_{j}},
$$

where $x_{j}$ is the encoded value of a factor; $\bar{x}_{j}$ is the natural value of a factor; $\bar{x}_{j(i)}$ is the natural value of the basic level; $I_{j}$ is the variation interval; $j$ is the number of the factor.

The basic level and the variation interval of the controlled factors are given in Table 1, while the matrix of the experimental design is presented in Table 2 (the last 5 columns present the experimental results).

The following characteristics of expanded polystyrene were determined under the conditions of constant (long-term) compression of the specimens, which were cut from EPS slabs and selected according to the experiment design matrix: $y_{1}$ is creep compliance $I_{c}$, 
$\mathrm{MPa}^{-1}$, at time $t_{n}=122$ days; $y_{2}$ is creep strain $\varepsilon_{c}, \%$, developed under constant compressive stress $\sigma_{c}=0.35 \sigma_{10 \%}$ during the experiment, $t_{n}=122$ days; $y_{3}$ is the predictive point estimate of creep strain, $\varepsilon_{c}(T), \%$, for the lead time of 10 years.

For describing the relationship between the factors $x_{i}$ and the output $y_{i}$ in the investigated domain, a quadratic model was used.

Table 1. Basic characteristics of experimental design

\begin{tabular}{|c|c|c|}
\hline Characteristic & $\begin{array}{c}\text { Density of EPS specimens, } x_{1}, \\
\mathrm{~kg} / \mathrm{m}^{3}\end{array}$ & $\begin{array}{c}\text { Thickness of EPS specimens, } x_{2}, \\
\mathrm{~mm}\end{array}$ \\
\hline Basic level & 19.3 & 75 \\
\hline Interval of variation & 4.0 & 25 \\
\hline Upper level & 23.3 & 100 \\
\hline Lower level & 15.3 & 50 \\
\hline
\end{tabular}

Table 2. Matrix of full factorial design of the type $3^{2}$ and the experimental results

\begin{tabular}{|c|c|c|c|c|c|c|c|}
\hline \multirow{2}{*}{$\begin{array}{c}\text { Number of } \\
\text { experiments }\end{array}$} & \multirow{2}{*}{$x_{1}$} & \multirow{2}{*}{$x_{2}$} & \multicolumn{2}{|c|}{$y_{1}, \mathrm{MPa}^{-1}$} & \multicolumn{2}{|c|}{$y_{2}, \%$} & $y_{3}, \%$ \\
\hline & & & $\bar{y}_{1}{ }^{*}$ & $S_{y_{1}}$ & $\left.\bar{y}_{2}{ }^{*}\right)$ & $S_{y_{2}}$ & $\bar{y}_{3}^{\text {pred. }}$ \\
\hline 1 & -1 & -1 & 0.3564 & 0.0077 & 1.0239 & 0.0220 & 2.163 \\
\hline 2 & 0 & -1 & 0.2019 & 0.0153 & 0.8206 & 0.0622 & 2.203 \\
\hline 3 & +1 & -1 & 0.0842 & 0.0117 & 0.4426 & 0.0618 & 1.074 \\
\hline 4 & -1 & 0 & 0.3117 & 0.0248 & 0.8652 & 0.0772 & 2.420 \\
\hline 5 & 0 & 0 & 0.1792 & 0.0053 & 0.7263 & 0.0214 & 2.055 \\
\hline 6 & +1 & 0 & 0.0760 & 0.0072 & 0.3980 & 0.0374 & 0.927 \\
\hline 7 & -1 & +1 & 0.3138 & 0.0180 & 0.8920 & 0.0524 & 2.065 \\
\hline 8 & 0 & +1 & 0.1847 & 0.0095 & 0.7421 & 0.0324 & 2.262 \\
\hline 9 & +1 & +1 & 0.0719 & 0.0019 & 0.3689 & 0.0102 & 0.873 \\
\hline
\end{tabular}

${ }^{*}$ Mean values of output parameters $y_{1}, y_{2}$ for three parallel determinations.

Output settings:

$\boldsymbol{y}_{1}: \sum_{i=1}^{N} S_{y_{1}}^{2}=0.001543, G=\frac{S_{y_{1}(\max )}^{2}}{\sum_{i=1}^{N} S_{y_{1}}^{2}}=0.399, \quad S_{\text {reprod. }}^{2}=\frac{S_{y_{1}}^{2}}{N}=0.000171, S_{b j}=\sqrt{\frac{S_{\text {reprod. }}^{2}}{N m}}=0.00252$.

$\boldsymbol{y}_{2}: \sum_{i=1}^{N} S_{y_{2}}^{2}=0.020314, G=0.293, S_{\text {reprod. }}^{2}=0.00226, S_{b j}=0.00914$.

$\boldsymbol{y}_{3}: S_{\text {reprod. }}^{2}=0.00226, S_{b j}=0.00914$.

The table values: $G_{1-\alpha(2 ; 9)}=0.478, t_{1-\alpha(18)}=2.10$ (if $\alpha=0.05$ ), $G$ - Cochran's test, $t$ Student's t test.

In general, a quadratic model may be expressed by the equation:

$$
y=b_{0}+b_{1} x_{1}+b_{2} x_{2}+b_{12} x_{1} x_{2}+b_{11} x_{1}^{2}+b_{22} x_{2}^{2}
$$

The significance of constant coefficients was validated by the Student's $t$-statistic at the significance level $\alpha=5 \%$. Non-significant coefficients were not included in the equation. The adequacy of Eq. (6) was tested by Fisher's criterion [13, 14].

\section{Results}

In Fig. 1, the experimental values and the regression lines of the compressive stress $\sigma_{10 \%}$ based on the results obtained in determining density $\rho$ of the specimens, as well as the 
regression dependence from EN 13163 (Fig. 1, line 2), are presented. In accordance with EN 13163, a linear dependence, approximated based on the experimental data by the regression equation (line 1), was used: $\bar{\sigma}_{10 \%}=8.9 \rho-55.5$, with the standard deviation $S_{r}=3.64 \mathrm{kPa}(n=107)$.

The minimum predictive estimates, $\bar{\sigma}_{10 \%}^{\min }$, were approximated by the equation (Fig. 1 , line 3): $\bar{\sigma}_{10 \%}^{\min }=8.9-59.7$.

Table 3. Experimental test data and results of the regression analysis of creep deformation of polystyrene specimens under constant compressive stress $\sigma_{c}=0.35 \sigma_{10 \%}$

\begin{tabular}{|c|c|c|c|c|c|c|c|c|c|c|c|}
\hline \multirow{3}{*}{ 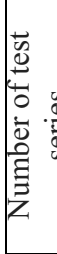 } & \multicolumn{7}{|c|}{$\begin{array}{l}\text { The test data for specimens under } \\
\text { compressive stress }\end{array}$} & \multicolumn{3}{|c|}{ Regression analysis data ${ }^{a}$} & \multirow{3}{*}{$\begin{array}{c}\text { The predicted } \\
\text { point values of } \\
\text { creep strain } \\
\bar{\varepsilon}_{c}(T=10 \text { years })^{e} \\
\%\end{array}$} \\
\hline & \multicolumn{2}{|c|}{ Shor-term $^{b}$} & \multicolumn{5}{|c|}{ Long-term $^{c}$} & \multicolumn{2}{|c|}{$\begin{array}{c}\text { Constant } \\
\text { coefficients in } \\
\text { Eq. (5) }\end{array}$} & \multirow{2}{*}{$\begin{array}{c}\sum_{i=1}^{n}\left(y_{3(i)}-\bar{y}_{3(i)}\right)^{2} \\
\%^{d}\end{array}$} & \\
\hline & $\begin{array}{c}\rho, \\
\mathrm{kg} / \mathrm{m}^{3}\end{array}$ & $\begin{array}{l}\sigma_{10 \%}, \\
\mathrm{kPa}\end{array}$ & $\begin{array}{c}\rho, \\
\mathrm{kg} / \mathrm{m}^{3}\end{array}$ & $\begin{array}{c}d_{s}, \\
\mathrm{~mm}\end{array}$ & $\begin{array}{c}\sigma_{c}, \\
\mathrm{kPa}\end{array}$ & $\varepsilon_{0}, \%$ & $\begin{array}{c}\varepsilon_{c}\left(t_{n}\right) \\
\%\end{array}$ & $b_{0}$ & $b_{1}$ & & \\
\hline 1 & 15.4 & 82.1 & 15.3 & 48.0 & 28.7 & 1.374 & 1.0239 & 0.1520 & 0.2333 & 0.01329 & 2.163 \\
\hline 2 & \begin{tabular}{|l|}
19.3 \\
\end{tabular} & 116 & 19.2 & 49.4 & 40.6 & 1.155 & 0.8206 & 0.0738 & 0.2984 & 0.00426 & 2.203 \\
\hline 3 & 23.8 & 152 & 23.6 & 48.6 & 52.6 & 1.277 & 0.4426 & 0.0333 & 0.3222 & 0.00071 & 1.074 \\
\hline 4 & 15.1 & 78.5 & 15.3 & 72.8 & 27.7 & 1.145 & 0.8652 & 0.0989 & 0.2809 & 0.01100 & 2.420 \\
\hline 5 & \begin{tabular}{|l|}
19.3 \\
\end{tabular} & 116 & 19.3 & 74.4 & 40.5 & 0.951 & 0.7263 & 0.0582 & 0.3132 & 0.00253 & 2.055 \\
\hline 6 & 23.0 & 150 & 23.0 & 73.3 & 52.4 & 1,005 & 0.3980 & 0.0533 & 0.2511 & 0.00022 & 0.927 \\
\hline 7 & 15.3 & 81.1 & 15.3 & 98.2 & 28.4 & 0.985 & 0.8920 & 0.0814 & 0.2841 & 0.00 & 2.065 \\
\hline 8 & 19.3 & 115 & 19.3 & 99.5 & 40.2 & 0.767 & 0.7421 & 0.0490 & 0.3367 & 0.00 & 2.262 \\
\hline 9 & 23.0 & 147 & 23.0 & 98.0 & 51.3 & 0.932 & 0.3689 & 0.0427 & 0.2652 & 0.00137 & 0.873 \\
\hline
\end{tabular}

${ }^{a}$ Linear regression analysis was performed starting with the values of creep strain $\varepsilon_{c}(t=24 h) ;{ }^{b}$ The results of testing 12 specimens for selecting long-term compressive stress parameters; ${ }^{c} \rho, d_{s}, \sigma_{c}, \varepsilon_{0}$, $\varepsilon_{c}\left(t_{n}\right)$ are the average values for 3 specimens; ${ }^{d}$ The sums of standard deviations, $\mathrm{y}_{3(i)}$, from their estimated values, $\bar{y}_{3(i)}$, for the number of retrospective observations $n=18$; ${ }^{e}$ Calculated by time extrapolation EN 1606.

Thus, and the data obtained in creep tests may be used for describing the slabs of the types EPS $80^{2}$, EPS 100, EPS 120 and EPS 150.

In Table 3, the experimental data and the regression equation of the relative creep strains of expanded polystyrene specimens, calculated by Eq. (5) based on the experiments with the duration $t_{n}=122$ days, are given. The data obtained in their mathematical-statistical analysis are given in Table 4.

The coefficients of Eq. (6), calculated based on the data (encoded variables) found in Tables 2 are presented in Table 4 .

In general, we can see from the coefficient values in the equations that not all the factors equally affect the considered output parameters (Table 4). The regression coefficient is a quantitative measure of the effect exerted by a particular factor on an output parameter, when going from a zero level to the lower or higher levels. The larger the coefficient, the stronger the factor. The signs of the coefficients indicate the strength of the factor's influence.

Table 4. Coefficient values of regression equations based on coded variables

\begin{tabular}{l|l} 
Coefficient & Coefficient \\
\hline
\end{tabular}

\footnotetext{
2 According to EN 13163, these are the EPS slabs with the compression stress at $10 \%$ deformation $\sigma_{10 \%}$ equal to $80,100,120$ and $150 \mathrm{kPa}$, respectively.
} 


\begin{tabular}{|c|c|c|c|c|c|c|}
\hline $\begin{array}{c}\text { value for } \\
\text { equations }\end{array}$ & $b_{0}$ & $b_{1}$ & $b_{2}$ & $b_{12}$ & $b_{11}$ & $b_{22}$ \\
\hline$y_{1}$ & 0.1798 & -0.1250 & -0.0120 & 0.00758 & 0.0137 & 0.0132 \\
\hline$y_{2}$ & 0.7284 & -0.2619 & -0.0474 & - & -0.0979 & 0.0518 \\
\hline$y_{3}$ & 2.1916 & -0.6290 & -0.0400 & -0.0257 & -0.5863 & -0.0273 \\
\hline
\end{tabular}

\section{Discussion}

Considering the equation for the parameter $y_{1}$, we have found that the extremum point

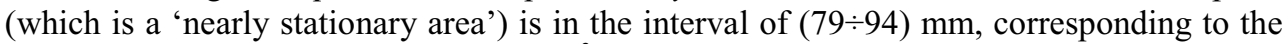
variation of $x_{1}$ from 23.3 to $15.3 \mathrm{~kg} / \mathrm{m}^{3}$. The investigation results for $y_{2}$ show that the extremum point, $y_{2}$, at which the parameter $y_{2}$ is minimum with respect to the specimens, is the point $x_{2}=86 \mathrm{~mm}$. Considering the equation for the parameter $y_{3}$, we have found that, when $x_{1}$ varies from 15.3 to $23.3 \mathrm{~kg} / \mathrm{m}^{3}$, the extremum point $x_{2}$ ('almost stationary area') is in the interval of $(68 \div 45) \mathrm{mm}$.

When we considered natural (real) variables instead of the coded variables and averaged the regression coefficients, the equations for the output parameters took the form of with the standard deviation $S_{r}=0.0052 \mathrm{MPa}^{-1}(N \cdot m=27$ test results).

$$
\begin{gathered}
I_{c}\left(t_{n}=122\right)=1.3664-0.0700 \cdot \rho-0.00511 \cdot d+0.0000758 \cdot \rho \cdot d+0.000856 \cdot \rho^{2}+0.0000211 \cdot d^{2}, \\
\varepsilon_{c}\left(t_{n}=122\right)=0.3213+0.1707 \cdot \rho-0.0143 \cdot d-0.00612 \cdot \rho^{2}+0.000083 \cdot d^{2} \\
{\left[S_{r}=0.0212 \%, N \cdot m=27\right]} \\
\varepsilon_{c}(T=10 \text { years })=-8.9209+1.2765 \cdot \rho+0.0099 \cdot d- \\
-0.0002575 \cdot \rho \cdot d-0.03664 \cdot \rho^{2}-0.0000437 \cdot d^{2} \\
{\left[S_{r}=0.180 \%, N \cdot m=9\right] .}
\end{gathered}
$$

When the value of the factor $x_{I}$ (EPS density) is fixed at three levels, the figures present the relationships between the output parameters $I_{c}$ and $\varepsilon_{\mathrm{c}}$ and the factor $x_{2}$ (specimen thickness), proving the existence of a particular optimum, i.e. 'nearly stationary area', corresponding to this factor (dotted lines in Figures $2 \mathrm{a}$ and $3 \mathrm{a}$ ).
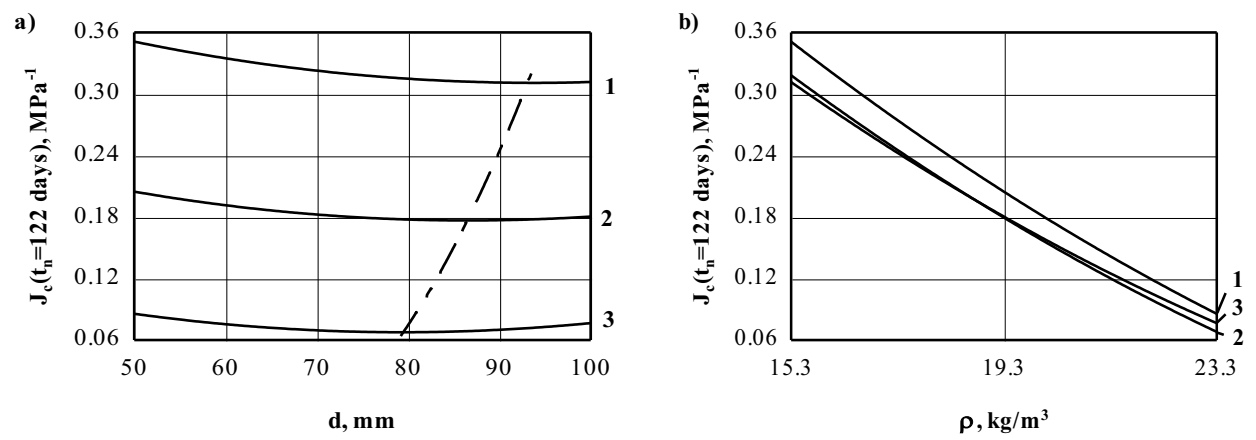

Fig. 2. Graphs of Eq. (7): a) when $\rho=15.3$ (1); 19.3 (2); $23.3 \mathrm{~kg} / \mathrm{m}^{3}$ (3); b) when $d=50$ (1); 75 (2); 100 $\mathrm{mm}$ (3). A dotted line represents a 'nearly stationary area'. 

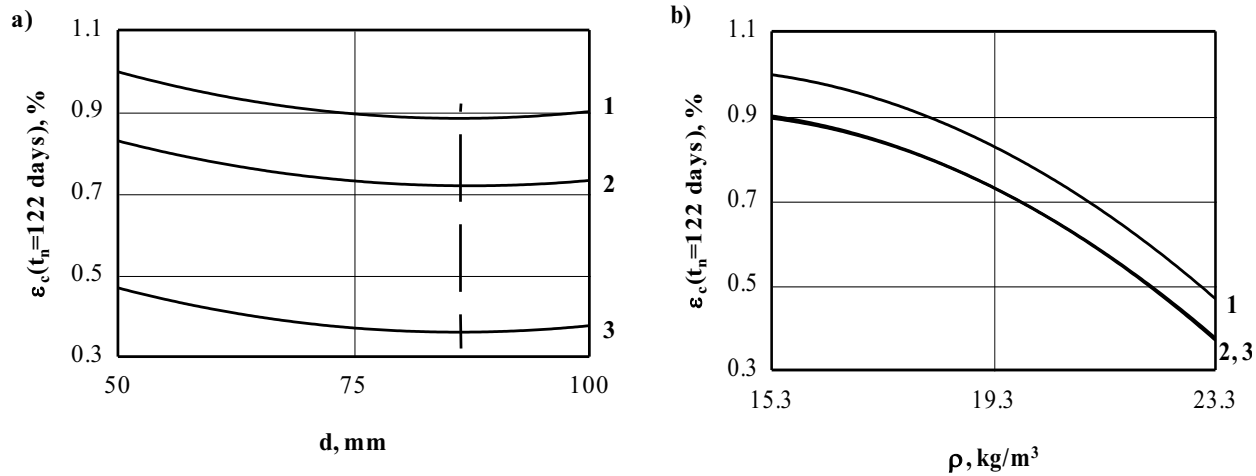

Fig. 3. Graphs of Eq. (8). The notation is the same as given in Fig. 2.

Considering the response generators of the output parameters $I_{c}$ and $\varepsilon_{c}$, with the value of factor $x_{2}$ (specimen thickness) fixed at three levels, we presented (Figures $2 b$ and $3 b$ ) the dependences of the output parameters on factor $x_{I}$ (specimen density). When the density of the EPS specimens is in the range of $15.3-23.3 \mathrm{~kg} / \mathrm{m}^{3}$, creep compliance, $\left(I_{c}\right)$, values determined for $50 \mathrm{~mm}$-thick specimens is $15 \%$ higher than that for 75 and $100 \mathrm{~mm}$-thick specimens (when $d$ is equal to 75 and $100 \mathrm{~mm}$, the values of $I_{c}\left(t_{n}=122\right.$ days) are actually equal).

The value of the creep strain $\varepsilon_{c}\left(t_{n}=122\right.$ days $)$ in EPS density range of $15.3-23.3 \mathrm{~kg} / \mathrm{m}^{3}$, when specimen thickness varies from 50 to $(75$ and 100) $\mathrm{mm}$, decreases by about 11 and $26 \%$ (rel.) ${ }^{3}$ with respect to its density (Fig. 3b). The creep strains $\varepsilon_{c}\left(t_{n}=122\right.$ days) of 75 and $100 \mathrm{~mm}$-thick specimens are actually equal. It is worth noting that, in the considered EPS density range, the absolute values of $\varepsilon_{c}\left(t_{n}=122\right.$ days) obtained for $50 \mathrm{~mm}$-thick specimens and 75 and $100 \mathrm{~mm}$-thick specimens differ by $0,1 \%$ [15].

In Fig. $4 b$, the dependence of the output parameter of the creep strains $\varepsilon_{c}(T=10$ years) on the factor $x_{1}$ (EPS density) are presented for the factor $x_{2}$ fixed at three levels. When EPS density is $15.3-23.3 \mathrm{~kg} / \mathrm{m}^{3}$, and the specimens are 50 and $75 \mathrm{~mm}$-thick, the predictive point estimates of $\varepsilon_{c}(T=10$ years), calculated according to their density, are by $(2-13) \%$ (rel.) larger than those found for $100 \mathrm{~mm}$-thick specimens.
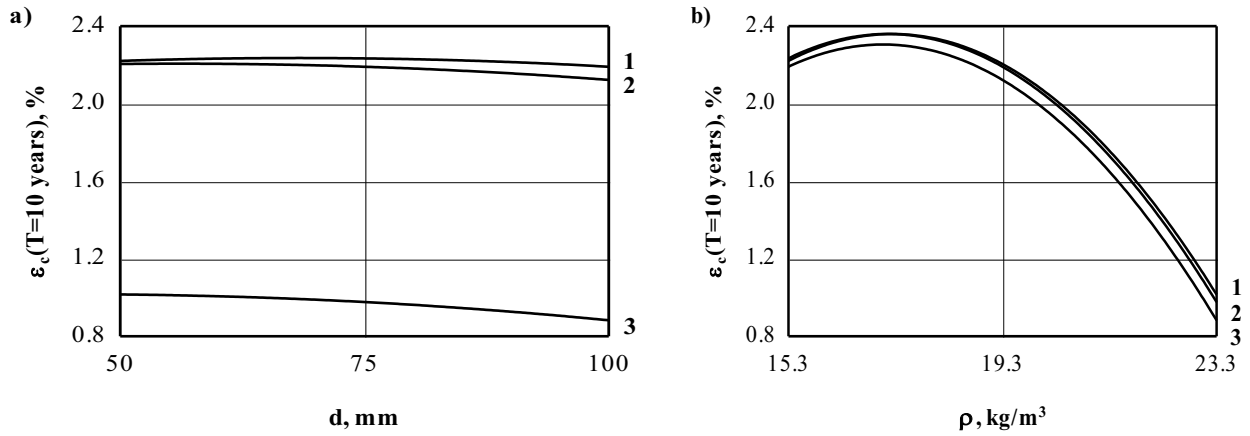

Fig. 4. Graphs of Eq. (9). The notation is the same as given in Fig. 2.

It should be noted that the obtained equations (3-5) may be used in practice for estimating the creep strains at time $t=122$ days and the predictive estimates of $\varepsilon_{c}(T=10$ years) for the lead time of 10 years.

${ }^{3}$ The abbreviation (rel.) indicates a relative difference in values, when creep strain $\varepsilon_{c}$ is measured in percent. 


\section{Conclusions}

In conclusion, it is necessary to mention that the mathematical models for determining $I_{c}\left(t_{n}=122\right.$ days $), \varepsilon_{c}\left(t_{n}=122\right.$ days $)$ and $\varepsilon_{c}(T=10$ years $)$ of expanded polystyrene specimens under constant compressive stress $\sigma_{\mathrm{c}}=0.35 \sigma_{10 \%}$ have been constructed, using a method of experimental design.

The empirical equations (3-5) for determining the predictive estimates of creep compliance $I_{c}(t=122$ days $)$, creep strains $\varepsilon_{c}(t=122$ days $)$ and $\varepsilon_{c}(T=10$ years $)$ for the lead time of 10 years have been obtained for expanded polystyrene slabs with the density of $15.3-$ $23.3 \mathrm{~kg} / \mathrm{m}^{3}$.

In EPS density range of $15.3-23.3 \mathrm{~kg} / \mathrm{m}^{3}$ and under the variation of specimen thickness from 50 to $(75$ and 100$) \mathrm{mm}$, the experimental value of the creep strain $\varepsilon_{c}(t=122$ days) decreases by about 11 and $26 \%$ (rel.) with respect to its density. The influence of specimen thickness on the predictive estimates of the creep strains for the lead time of 10 years $\varepsilon_{c}(T=10$ years $)$ is insignificant. In EPS density range of $15.3-23.3 \mathrm{~kg} / \mathrm{m}^{3}$, the values of $\varepsilon_{c}(T=10$ years), calculated from the experimental data obtained for specimens with the thickness of 50 and $75 \mathrm{~mm}$, are by $2-13 \%$ (rel.) larger compared to $100 \mathrm{~mm}$ thick specimens.

The work carried out in accordance with the local project "Conducted in the field of energy saving and energy efficiency of buildings and structures" in accordance with the plan of research works of MSUCE. Work was carried out on the basis of the initiative.

\section{References}

1. U. Knaack, Sh. Chung-Klatte, R. Hasselbach, Prefabricated systems: Principles of construction (De Gruyter, 2012)

2. I.J. Gnip, V.J. Keršulis, S.J. Vaitkus, Mechanics of Composite materials, 41(4), 357 (2005)

3. A.D. Zhukov, N.V. Naumova, R.M. Mustafayev, Industrial and civil building, 7, 39 (2014)

4. I. Gimenez, M.K.Faroog, A. El Mahi, A. Kondrotas, M. Assarar, Materials Science (Med iagotyra), 10 (1), 34 (2004)

5. V.I. Telichenko, D.V. Oreshkin, Ecology of urbanized areas, 2, 31 (2015)

6. B.M. Rumiantcev, A.D. Zhukov, D.B. Zelenshikov, A.S. Chkunin, K.K. Ivanov, Yu.V. Sazonova, MATEC Web of Conferences, 86 (2016)

7. A.D. Zhukov, E.Yu. Bobrova, D.B. Zelenshchikov, R.M., A.O. Khimich, Advanced Materials, Structures and Mechanical Engineering, 1025-1026, 1031 (2014)

8. J.S. Horvath, Manhattan College Research report, 39 (No CE/GE-98-3, New-York, USA, 1998)

9. B.M. Rumiantcev, A.D. Zhukov, E.Yu. Bobrova, I.P. Romanova, D.B. Zelenshikov, T.V. Smirnova, MATEC Web of Conferences, 86 (2016)

10. A.D Zhukov, I.V. Bessonov, A.N. Sapelin, N.V. Naumova, A.S. Chkunin, Italian Science Review, 2, 155 (2014)

11. P.R. Head, Proceedings of the ICE - Civil Engineering, 144(3), 113 (2001)

12. A.D .Zhukov, A.B. Chugunkov, Vestnik MGSU, 1-2, 273 (2011)

13. I.J. Gnip, V.J. Keršulis, Construction Materials, 4, 22. (2003)

14. I.J. Gnip, V.J. Keršulis, S.J. Vaitkus, Mechanics of Composite materials, 41(5), 407 (2005)

15. I.J .Gnip, S.Vaitkus, V. Keršulis, S. Vejelis, Polymer Testing, 29, 693 (2010) 